\title{
A atualidade das contribuições de Moisey $M$. Pistrak e Viktor N. Shulgin para a pedagogia do Movimento dos Trabalhadores Sem Terra
}

\author{
Franciele Soares dos Santos* \\ Conceiçáo Paludo**
}

\section{Resumo}

O objetivo deste artigo é contribuir para o debate sobre a atualidade da pedagogia socialista para os avanços da Pedagogia do Movimento dos Trabalhadores Sem Terra (MST), por meio da proposta de implementaçáo do plano de estudos de Moisey M. Pistrak e da categoria do trabalho socialmente necessário, elaborada por Viktor N. Shulgin. Para a sua elaboração, foi realizado estudo bibliográfico dos autores citados, assim como das obras de Caldart e de documentos do MST. Os resultados indicam que o MST ensaia e engendra, na atualidade, estabelecendo o diálogo com os educadores russos, a possibilidade de construção de uma pedagogia pautada nos princípios da pedagogia socialista, cuja categoria central é o trabalho. Conclui-se que, ao estabelecer relaçôes comprometidas com os sujeitos concretos, objetivar a consciência crítica da realidade e o compromisso com a luta social do Movimento, essa experiência vem alterando, além do conteúdo, o método e a forma escolar.

Palavras-chave: Educação Socialista. Movimento dos Sem Terra. Trabalho e Educação.

\footnotetext{
* Mestra em Educaçáo pela Universidade Federal de Santa Catarina (UFSC). Doutoranda em Educaçáo na Universidade Federal de Pelotas (UFPEL). Professora do Curso de Pedagogia da Universidade Estadual do Oeste do Paraná (UNIOESTE).

** Doutora em Educaçăo pela Universidade Federal do Rio Grande do Sul (UFRGS). Professora da Faculdade de Educaçáo e do Programa de Pós-Graduaçâo em Educação na Universidade Federal do Rio Grande do Sul (UFRGS).
} 


\section{Introdução}

Este texto parte do pressuposto de que o Movimento dos Trabalhadores Sem Terra, junto a outros movimentos sociais populares do campo, engendra processos educacionais que sinalizam avanços qualitativos no âmbito da formação humana. E também demonstra a possibilidade da construção de um projeto alternativo de sociedade, no contexto do modo de produçáo capitalista, situando a educaçáo no âmbito da luta contra-hegemônica.

O foco da reflexão está na necessidade de investigar a atualidade das contribuiçôes da pedagogia socialista para a Pedagogia do Movimento Sem Terra (MST), por meio da proposta do plano de estudos de Moisey M. Pistrak $(2003,2009)$ e da categoria "trabalho socialmente necessário", pensada por Viktor N. Shulgin (2013).

A pesquisa bibliográfica, neste caso, foi realizada por meio estudo das principais obras escritas, traduzidas para o português, pelos pedagogos socialistas Moisey M. Pistrak e Viktor N. Shulgin, respectivamente, Fundamentos da escola do trabalho, A escola-comuna e Rumo ao Politecnismo. Além de leituras de bibliografias que discutem a educação no MST, bem como a Pedagogia do Movimento Sem Terra, especialmente as obras de Caldart (1997, 2002). Já o estudo documental foi feito a partir de leitura e análise de alguns materiais elaborados pelo setor de Educaçáo do movimento: o Dossiê MST Escola: documentos e estudos de 1990 a 2001 (MST, 2005) e Caderno n. 8: Princípios da educação no MST(MST, 1996).

Primeiramente, são tecidas consideraçóes a respeito da constituição da escola única do trabalho no contexto da Revoluçáo Russa, seus princípios teóricos e metodológicos a partir de dois de seus representantes: Moisey Pistrak e Viktor Shulgin. Posteriormente, apresenta-se uma breve exposição da história do processo de elaboração da Pedagogia do Movimento Sem Terra, estabelecendo relaçôes com as fontes da sua proposta educacional, dando destaque ao processo de retomada da Pedagogia Socialista por meio do plano de estudos.

Por fim, são apontadas algumas contribuições sobre a utilização dos planos de estudos e da categoria trabalho socialmente necessário na reformulação do conteúdo, método e da forma escolar da Pedagogia do Movimento Sem Terra nos últimos anos no estado do Paraná.

Sabe-se que não é possível esgotar o debate sobre essas questóes com este artigo, uma vez que a proposta de implementaçấo dos planos de estudos ainda está sendo realizada nas escolas de educaçấo básica vinculadas ao Movimento. No entanto, acredita-se ser importante socializar algumas reflexóes preliminares e resultados já alcançados, que permitam contribuir no debate coletivo, no sentido de conhecer as 
possibilidades de construção de uma experiência de alteração da forma escolar capitalista, em espaços como dos movimentos sociais populares do campo, nesse caso específico o MST.

\section{A escola única do trabalho em Pistrak e Shulgin}

É especialmente durante o período revolucionário russo ${ }^{1}$ que pensadores como Vladimir Lênin, Nadjla Krupskaia, Moisey Pistrak, Anton Makarenko e Viktor Shulgin desenvolvem uma proposta pedagógica revolucionária em consonância com o movimento socialista. De acordo com Manacorda (1991), os embates pedagógicos entre pensadores e pedagogos burgueses e pensadores e pedagogos socialistas tomam corpo a partir do movimento que resultou na Revolução Russa em 1917, quando o proletariado e seu partido político instauraram o Estado Socialista².

Porém, as transformaçôes sociais, políticas, econômicas e também educacionais tão almejadas pelos revolucionários não ocorreram tão rapidamente. Segundo Rossi (1981, p. 12), “[...] na nova situaçáo tudo estava por ser feito. O mesmo também ocorreu no campo da educação, onde a revolução foi um desafio à criação de uma via inteiramente nova pela qual o povo russo poderia caminhar em direção ao socialismo".

Diante desse cenário, houve várias tentativas por parte dos educadores russos para a criação de uma nova pedagogia. Mas somente em 1931 ocorre a primeira reforma educacional na Uniáo Soviética, que tinha como intuito romper com os resquícios da educação tzaristas - verbalistas que ainda assombrava a possibilidade da construção de uma nova escola.

No começo da revoluçáo a tarefa colocada para a escola pela reviravolta revolucionária parecia, possivelmente, menos difícil e complicada do que parece para nós agora. A tarefa de construçáo da nova escola foi assumida por muitos pedagogos. A maioria sabia apenas uma coisa: que a nova escola náo deveria parecer-se com a antiga, que nela deveria reinar um espírito completamente diferente, que náo podia esmagar a personalidade da criança, como foi esmagada pela escola antiga. Os professores pioneiros da nova escola começaram seu difícil trabalho. Era preciso abrir uma picada na floresta virgem, trabalhar por sua conta e risco, observar incansavelmente, buscar, cometer erros e aprender com eles. (KRUPSKAIA, 2009, p. 105-106).

Como Krupskaia (2009), Pistrak foi um destes educadores socialistas. Escreveu em 1924 a obra Osproblemas fundamentais da Escola do Trabalho, (PISTRAK, 2003), na qual apresenta elementos essenciais para a compreensão da proposta educacional 
socialista. Para Pistrak (2003), o desenvolvimento de uma educação baseada nos fundamentos do socialismo se torna necessário à compreensão de três elementos centrais: (a) sem teoria pedagógica revolucionária não pode haver prática pedagógica revolucionária; (b) a teoria marxista é a teoria da transformação; (c) a teoria pedagógica comunista só se tornará ativa e eficaz quando o próprio professor assumir o papel de um militante social ativo no seio da nova escola.

A teoria pedagógica revolucionária é a teoria marxista, a qual o autor denomina, ao longo de sua obra, de "a teoria da transformaçáo", sendo imprescindível a instrumentalização dos alunos com ensino do conhecimento científico e da filosofia marxista; somente assim a classe trabalhadora poderá almejar a transformação social.

[...] o marxismo nos dá não apenas a análise das relações sociais, não somente o método de análise para compreender a essência dos fenômenos sociais suas relaçóes recíprocas, mas também o método de ação eficaz para transformar a ordem existente no sentido determinado pela análise. (PISTRAK, 2003, p. 38).

A partir dessas compreensôes que se constituíram as bases da Escola Única do Trabalho $^{3}$, que norteavam a ação pedagógica nas Escolas Comunas, quais sejam: trabalho, a ligação com a atualidade, autogestão e a auto-organização dos estudantes.

É importante ressaltar, ainda, que Pistrak contou com as contribuiçốes de Shulgin para a realização de seus escritos, principalmente na obra Escola-Comuna. Os dois "[...] compartilhavam várias categorias [...] atualidade, autogestão e trabalho" (FREITAS, 2009, p. 22).

A importância atribuída à categoria trabalho se articula com a necessidade de transformar o trabalho "[...] como objeto de estudo, o trabalho como método, trabalho como fundamento da vida" (FREITAS, 2009, p. 32). É a partir dessa necessidade que emerge a categoria trabalho socialmente útil.

O trabalho socialmente útil é, exatamente, o elo perdido da escola capitalista. $\mathrm{O}$ trabalho socialmente útil é a conexão entre a táo propalada teoria e a prática. É pelo trabalho, em sentido amplo, que esta relação se materializa. Daí a máxima: não basta compreender o mundo, é preciso transformá-lo. A escola é um instrumento de luta no sentido de que permite compreender melhor o mundo (domínio da ciência e da técnica) com a finalidade de transformá-lo, segundo os interesses e anseios da classe trabalhadora (do campo e da cidade), pelo trabalho. (PISTRAK, 2009, p. 34). 
Portanto, o trabalho é o princípio educativo tanto para Shulgin quanto para Pistrak. O processo do trabalho assumia duas posiçôes: uma como possibilidade de inserção do princípio educativo do trabalho como atividade escola e outra como um fenômeno específico das disciplinas.

Desse modo, o pensamento pedagógico socialista compreendia o trabalho como $o$ solo básico, no qual organicamente crescera todo trabalho educativo-formativo da escola, como um todo único inseparável.

A leitura das obras permitiu constatar ainda que métodos escolares propostos pelos dois pedagogos são ativos e vinculados ao trabalho manual (trabalhos domésticos, trabalhos em oficinas com metais e madeiras, trabalhos agrícolas, desenvolvendo a aliança cidade-campo), ao trabalho agrícola ou ao trabalho industrial, nos quais os alunos deveráo estar inseridos, de forma que participem em todas as modalidades segundo suas capacidades. A intençâo do pensador era propiciar aos alunos a compreensão da totalidade do mundo do trabalho. Por sua vez, os métodos de trabalho educativo apresentavam:

[...] um momento de participação imediata no trabalho desde as suas mais simples formas (trabalho individual no autosserviço, cuidados pessoais) até mais complexas possíveis (trabalho na fábrica); em segundo lugar, um momento náo menos importante de estudo do trabalho com a participação no trabalho (até o trabalho na fábrica) ou sem participação imediata (estudo de formas mais amplas e complexas da indústria, estudo de toda a modernidade, até as manifestaçóes mais elevadas da cultura, como superestruturas em cima de inter-relaçôes econômicas, a saber, de trabalho). (PISTRAK, 2009, p. 216, grifos do autor).

De fato, por muito tempo a comuna escolar se pautou no autosserviço, realizado pelas crianças e pelos pedagogos. Na avaliação do educador, o fator que influenciou esta questão foi à necessidade que provinha das condiçôes materiais de existência. Para as crianças ficavam os autosserviços pessoais, como arrumar a cama, remendos, costuras, além de limpeza do prédio, auxílio em atividades na cozinha, na cantina, sauna e lavanderia, na calefação do prédio, na sala hospitalar e ambulatórios. Assim, de acordo com Pistrak (2009, p. 224-225),

Na nossa Escola-Comuna toda organização do trabalho de autosserviço encontra-se nas mãos das crianças. Administra todo este trabalho um mentor do Comitê Organizacional, que chefia a parte econômica. Seguem, em ordem de subordinação, o Comitê de Higiene, a Chefia da Enfermaria, a Chefia da 
Cantina, etc. [...] O tempo de trabalho distribui-se de forma a não atrapalhar os estudos escolares e não tirar as crianças para o trabalho neste tempo.

O autosserviço compreende a realização do trabalho combinado com a vida, o trabalho para si e para os outros, o que culminou na tentativa sem êxito de construir um sistema educativo e formativo pelo autosserviço. A organização do trabalho partia da divisão dos alunos em grupos e de uma espécie de rodízio nas atividades, e estas não podiam comprometer as aulas das crianças. $\mathrm{O}$ trabalho ainda contava com o controle inicial de um monitor de cada grupo, desenvolvendo-se em três setores distintos como as oficinas, a fábrica e o trabalho de verão. Portanto, a relação da escola com o trabalho produtivo acontecia por meio da definição dos métodos de trabalho e das formas de trabalho, para os grupos mais novos nas oficinas escolares, e para os mais velhos o trabalho na fábrica. Na avaliação de Pistrak (2009, p. 140-141):

[...] o trabalho nas oficinas dever seu usado amplamente. Nelas os estudantes náo apenas obtêm hábitos de uso de materiais; não apenas devem dar o material para esta ou aquela disciplina; nelas as crianças devem obter hábitos de auto-organização, de organização econômica da oficina, da divisão do trabalho; devem estudar o lado econômico-administrativo da oficina; a oficina deve ser um passo para a fábrica. [...] A fábrica é uma ampla porta para a vida; através desta porta para a vida, ela introduz-se na escola de forma organizada, reúnem-se todos os seus aspectos positivos e que elevam o desenvolvimento das crianças. A fábrica é também um meio de formação política e de fortalecimento da visão de mundo marxista das crianças. Portanto, a significaçâo principal da fábrica está em que ela é o princípio organizador da vida das crianças, impulsionador dos seus interesses: ela deve unir as crianças e desenvolver nelas a vontade coletiva, organizá-los.

Nesse contexto, a autodireção precisava caminhar de mãos dadas com os objetivos da escola do trabalho socialista. Pois, segundo Pistrak (2009, p. 270-271), “[...] a autodireção é percebida por nós não apenas como um método de trabalho educativo e formativo na escola, mas também como forma definida de uma determinada vida social das crianças”.

No que se refere à autogestão, esta deve ser ensinada desde a mais tenra idade e depende da construção da noção de coletividade, hábitos e habilidades de organização.

[...] a forma superior de autogestão é a assembleia geral de todos os membros, a comissão de organização [...] seu órgão executivo superior; ela distribui seus membros por uma série de 
conselhos escolares; ela toma conhecimento dos conflitos que ocorrem na comuna e toma uma série de medidas, promulgando deliberações. [...] a comissão de organização é construída de cinco pessoas: 1) administrador da parte econômica; 2) do internato; 3) do estudo; 4) do socialcientífico e 5) do secretariado. (SHULGIN, 2009, p. 31).

Assim, concomitante ao processo de autogestão ocorre a auto-organização dos estudantes, que está articulada a capacidade destes de trabalharem coletivamente; o que compreende responsabilidade, obrigaçóes e, principalmente, compromisso com a coletividade.

Já em relação à categoria atualidade, Pistrak (2009, p. 117-118) ressalta que:

[...] a tarefa básica da escola é o estudo da atualidade, o domínio e a penetração nela. Isso não significa, que a escola não deva familiarizar-se e estudar o passado coexistente [...] A escola deve formar nas ideias da atualidade; a atualidade deve, como um rio amplo, desembocar de forma organizada. A escola deve penetrar na atualidade e identificar-se com ela.

O estudo da realidade atual propiciaria aos educandos a compreensão da totalidade. Segundo Pistrak (2003, p. 35), é preciso demonstrar aos alunos que "os fenômenos que estáo acontecendo na realidade atual sáo simplesmente parte de um processo inerente ao desenvolvimento histórico geral, é preciso demonstrar a essência dialética de tudo que existe [...]”. A vivência da atualidade ocorreria por meio da escola, como forma de compreendê-la para assim lutar pela construção da nova sociedade sem classes. Nas palavras de Shulgin (2009, p. 24), “[...] nós precisamos da escola cada vez mais integralmente, de cima a baixo, impregnada pela atualidade; nós precisamos de professores que compreendam a atualidade, que tomem parte de sua reconstrução; nós precisamos que a criança viva-a”. Além disso, na Escola-Comuna de Pistrak o currículo da escola era organizado por meio do Plano de Estudos por complexo utilizado nas escolas soviéticas. De acordo com Freitas (2009, p. 37-38):

A noção de complexo de estudo é uma tentativa de superar o conteúdo verbalista da escola clássica, a partir do olhar do materialismo histórico-dialético, rompendo com a visão dicotômica entre teoria e prática (o que se obtém a partir da centralidade do trabalho socialmente útil no complexo). Ele não é um método de ensino, em si, embora demande, em associação a ele, o ensino a partir do trabalho socialmente útil é o elo, a conexão segura, entre teoria e prática, dada sua materialidade. 
O plano de estudo por complexo articula a transformação da forma e do conteúdo da escola, por meio da relação entre natureza, sociedade e trabalho. O que não significa dizer que a Escola-Comuna não trabalhasse com disciplinas escolares clássicas; trabalhava, mas de maneira transformada. Pois o complexo é uma construçáo da didática socialista (FREITAS, 2009), onde as categorias atualidade, auto-organização e trabalho são determinantes.

Com efeito, os princípios pedagógicos apresentados por estes e outros pedagogos socialistas foram estabelecidos a partir da necessidade da realização de uma teoria de caráter socialista em um determinado momento histórico. Porém, demonstram, ao mesmo tempo, que para a realização de uma práxis pedagógica coerente com pensamento pedagógico socialista é imprescindível considerar a íntima e necessária relação entre educação e trabalho no âmbito da formação humana, bem como compreender os pressupostos da filosofia marxista e, principalmente, lutar pela construção de uma proposta de educação contrária à lógica do capital. Portanto, no pensamento pedagógico socialista, a categoria trabalho ocupa lugar central.

\section{O trabalho em Marx: fundamento da pedagogia socialista}

Sobre a união trabalho e educação, esta se encontra localizada, inicialmente, na tradição herdada pelo socialismo utópico, sendo superada pelas análises de Marx e Engels a respeito das condições de vida e de trabalho. Logo, o debate sobre os fundamentos da teoria pedagógica socialista estáo diretamente vinculados aos pressupostos do materialismo histórico dialético.

Nos escritos marxianos, o trabalho apresenta-se como categoria central e, especialmente, é pelo trabalho que se constitui o processo teleológico. Segundo Lukács (1979), mesmo que, em Marx, a teleologia apareça no ato do trabalho, a tese marxiana avança em relação à concepção idealista de teleologia, pois afirma que o pôr-teleológico só pode ocorrer pelo processo de trabalho. Portanto, este só existe sob condiçóes reais, possuindo como premissa a capacidade do ser humano objetivar-se pelo processo de trabalho e, para, além disso, refletir suas açôes e suas atividades.

Nesse sentido, o homem, por meio de seu trabalho, transforma a matéria-prima provinda da natureza em coisas úteis para sua existência, o que está relacionado intrinsecamente com o ato teleológico. Pode-se compreender, entáo, que pelo processo de trabalho ocorre o salto qualitativo do "ser em-si" para o "ser para-si", ou seja, explicase a questáo do trabalho como fundamento ontológico do gênero humano, como criatura genérica. 
O homem é uma criatura genérica, não só na acepção de que faz objeto seu, prática e teoricamente, a espécie (tanto a sua própria como a das outras coisas), mas também - e agora trata-se apenas de outra expressão para a mesma coisa - no sentido de que ele se comporta diante de si mesmo como a espécie presente, viva, como um ser universal e portanto livre. (MARX, 2006, p. 115).

Dessa maneira, os pressupostos filosóficos da teoria marxiana postulam que é pelo trabalho que, primeiramente, o ser humano constituiu-se em sua formação histórica e social, pois, ao transformar a natureza por meio do processo de trabalho, promove em si o salto ontológico, ou seja, a passagem da esfera orgânica para a social, fundando em si a esfera social do ser.

No entanto, é preciso considerar que o trabalho sob os efeitos da divisão social do trabalho imposta historicamente pelo capitalismo torna-se alienado. $\mathrm{O}$ trabalho alienado oculta a essência do processo de trabalho, desconsiderando as aptidóes e capacidades dos indivíduos e suas necessidades fundamentais, suas aspiraçóes criadoras e os faz trabalhar para o capital como se estivessem trabalhando para si mesmos.

Assim, o produto do trabalho distancia-se do trabalhador porque foi produzido por ordens alheias e não por necessidades e capacidades do próprio trabalhador; porque fica exposto num mercado de consumo inalcançável para o trabalhador; e porque aparece como uma coisa existente em si e por si mesma e náo como resultado da açáo do trabalhador. Esse tríplice distanciamento é o processo social em que o trabalhador individual e a classe trabalhadora não podem reconhecer-se como autores dos produtos de seu próprio trabalho.

Ao passar da condição humana à mercadoria, ao tornar-se coisa que produz coisas e perder sua própria humanidade. Assim, constitui-se a alienação ${ }^{4}$ do trabalho. Como o trabalhador é uma coisa que produz coisas, a relação social do trabalho com o capital (ou entre classes) aparece-lhe como se fosse uma relação entre coisas, ocultando a verdadeira realidade (LAFARGUE, 2000, p. 34).

$\mathrm{O}$ pensamento pedagógico socialista está diretamente ligado às discussóes pedagógicas situadas sob uma perspectiva marxista e atrelado a um projeto revolucionário de educação. Portanto, os debates pedagógicos no contexto da Revolução Russa tiveram por referência prática e teórica os textos clássicos de Marx e Engels, o que náo foi diferente com Pistrak e Shulgin, que se tornaram referência para o aprofundamento do conteúdo, método e da forma escolar da Pedagogia do Movimento Sem Terra nos últimos anos. 


\section{A educação no MST e o desafio de construção de um plano de estudos para as escolas públicas dos assentamentos no Estado do Paraná}

$\mathrm{Na}$ atualidade, os movimentos sociais populares do campo, em destaque o MST, representam o que há de mais avançado de luta contra-hegemônica no Brasil (FRIGOTTO, 2011). Representam elementos da história de lutas da classe trabalhadora e revelam o caráter essencialmente contraditório do capital, bem como a inevitável existência de classes antagônicas.

O Movimento dos Trabalhadores Rurais Sem Terra é, na atualidade, o principal movimento social do campo do Brasil. Trata-se de um movimento social, constituído historicamente pelos trabalhadores do campo no processo de luta pela terra e pela reforma agrária. Tem como elemento de luta social a contraposição à lógica capitalista e suas formas de opressão no campo.

Por meio de suas dinâmicas de organização, o movimento constituiu historicamente um espaço pelo qual se produzem processos educativos, ou seja, sujeitos pedagógicos (CALDART, 2004). Foi ao longo de sua trajetória que o MST gestou sua proposta educativa articulada com sua luta social. Suas açôes educativas visam à transformação social das condiçóes materiais de existência e à transformação das consciências dos sujeitos sem-terra.

Com efeito, o Movimento ${ }^{5}$ intensificou, cada vez mais, suas lutas neste sentido, principalmente a partir da necessidade que emergia da construção de uma escola no movimento e para o movimento. $\mathrm{O}$ que gerou a necessidade da elaboraçáo de uma proposta educacional, bem como a formação de educadores que trabalhassem nas escolas do assentamento de acordo com seus princípios pedagógicos.

Ao relatar a história da organização e luta dos pais e professores acampados e assentados pelo direito à escola para seus filhos, Caldart (1991) afirma que as discussóes abrangiam debates relativos à formação de educadores, pois, à medida que se criavam as escolas nos assentamentos e nos acampamentos, aumentava a demanda por professores.

Com a criação do Setor de Educação do Movimento em 1988, inicia-se a luta por um curso de magistério para formar educadores do movimento e para o movimento. Após muitas tentativas no âmbito do Estado, o Setor de Educação cria a Fundação de Desenvolvimento, Educação e Pesquisa da Região do Celeiro (FUNDEP). A FUNDEP 
é criada em 1989, no município de Três Passos, pela articulação de movimentos populares da região com alguns setores da Igreja e com o grupo de educadores dispostos a dar à luz proposta realmente nova de educação. Proposta que seja organicamente vinculada às necessidades e demandas da formação de uma população regional organizada, tanto na área do ensino formal como da educação não formal. (CALDART, 1991, p. 104).

A Fundação, por meio do Departamento de Educação (DER), em diálogo com o MST, elabora a proposta do curso de magistério para professores assentados. A primeira turma de magistério iniciou em 1990, em Braga, RS. Portanto, a educação no MST vai sendo gestada também a partir do fato de que havia professores de fora dos assentamentos educando as crianças em uma visão de mundo contrária à luta do movimento (CALDART, 1997).

Roseli Caldart, intelectual ligada ao movimento, foi quem sistematizou a proposta pedagógica do mesmo, por meio das obras: Educação em Movimento: formação de educadores e educadoras do MST (1996), Escola é mais do que escola na Pedagogia do Movimento (1999); e a obra publicada em 2004 descreveu as fases de elaboração da proposta educacional do MST, Pedagogia do Movimento Sem Terra. Esta última pesquisa se constituiu “[...] na primeira grande síntese teórico-prática da pedagogia do MST" (FRIGOTTO, 2011, p. 36). Um marco para a sistematização da proposta pedagógica do Movimento, uma obra referencial nas discussões sobre educação no âmbito do MST.

Segundo Caldart (2011, p. 148), "Pedagogia do Movimento foi o nome que demos a uma forma de práxis pedagógica que tem origem e referência no Movimento Social dentro ou desde um projeto de transformação da sociedade e do ser humano". Nesse sentido, uma formação vinculada aos princípios pedagógicos da Pedagogia do Movimento se caracteriza por ser uma formação político-pedagógica que repensa as práticas educativas a partir de específicas matrizes pedagógicas, apontando para uma ação de reflexão crítica na formação dos sujeitos do campo, questionando, por exemplo, a expropriação do modo de produção capitalista sobre os trabalhadores do campo.

Na obra Pedagogia do Movimento Sem Terra, a autora defende a tese do movimento como princípio educativo e apresenta a Pedagogia do Movimento Sem Terra constituída por diferentes matrizes pedagógicas: Pedagogia da luta social, Pedagogia da organização coletiva, Pedagogia da terra, Pedagogia do trabalho e da produção, Pedagogia da cultura, Pedagogia da escolha, Pedagogia da alternância e Pedagogia da história (CALDART, 2004).

Afirma também que três fontes influenciaram a elaboração da Pedagogia do Movimento: a experiência trazida pelos sujeitos que militavam no MST; o Movimento, 
seus princípios, projetos e ensinamentos; e, por último, os elementos da teoria pedagógica trazida pelos professores e pedagogos que auxiliavam o MST, em destaque os estudos de Paulo Freire e também de alguns pensadores e pedagogos socialistas (CALDART, 2004).

O que fica evidente nos princípios filosóficos sistematizados pelo movimento: educação para a transformação social; educação para o trabalho e cooperação; educação voltada para as várias dimensóes da formação humana; educação com e para valores humanistas e socialistas; e educação como um processo permanente de formação/transformação humana (MST, 1996). Princípios estes que o movimento tenta materializar de diferentes formas em suas práticas político-pedagógicas e a partir de

[...] um processo pedagógico que se assume como político, ou seja, que se vincula organicamente com os processos sociais que visam à transformação da sociedade atual e à construção, desde já, de uma nova ordem social, cujos pilares principais sejam a justiça social, a radicalidade e os valores humanistas e socialistas. (MST, 1996, p. 6).

Sabe-se que, por muito tempo, a proposta pedagógica do MST esteve baseada no trabalho com os temas geradores de Paulo Freire. Com efeito, o pensamento político-pedagógico freireano articulou-se aos desafios da construção de um projeto educativo emancipatório do MST, sendo presença constante nas experiências educativas.

A partir de estudos anteriores (SANTOS, 2009) e atuais que estão sendo realizados, constata-se que o pensamento político-pedagógico de Freire contribuiu com questóes fundamentais para a luta do MST, ao ensinar que "mudar é difícil, mas é possível", que a transformação social implica em sonho, utopia e projeto, ao demonstrar a "história como possibilidade", bem como a necessidade dos oprimidos assumirem os desafios da transformação, de assumir sua "presença" no mundo.

Como afirmou Bogo (2007, p. 7), intelectual vinculado ao MST, em seu texto "O pedagogo da esperança e da liberdade", "[...] Paulo Freire nos ensinou o caminho para a formação da consciência na sua forma política. Ensinou-nos que "estar no mundo e com o mundo" é não somente aprender a ler a realidade, mas propor-se a modificá-la”.

No entanto, nos últimos anos o MST retoma de forma mais incisiva a pedagogia socialista, por meio da organizaçáo da proposta do plano de estudos de Pistrak e Shulgin, no estado do Paraná. A metodologia dos temas geradores vem sendo substituída aos poucos. Desde meados de 2010, a proposta do plano de estudos de Pistrak está sendo implementada no Paraná, nas escolas itinerantes do MST, nos anos 
finais do Ensino Fundamental e no Ensino Médio. De acordo com Sapelli (2012, p. 67):

[...] o MST está retomando questóes que estavam presentes nos anos 1980, mas náo eram táo claras, pois os aprendizados que se tem na luta fazem retomar para avançar, aspectos que pareciam ser separados, vão sendo juntados, ou seja, os estudos sobre Pistrak e a proposta dos complexos iniciados nos anos 1980 foram retomados em 2010. O que motivou essa retomada foram encontros realizados em 2009, com representantes do MST, de universidades e do setor de Educaçáo do Paraná que se reuniram para registrar algumas experiências do Movimento, tanto do Paraná como de outros estados.

Com base nesta citação, pode-se inferir que a retomada da pedagogia socialista está relacionada com os aprendizados que estão em sintonia com as experiências educativas desenvolvidas no âmbito do movimento desde sua criação, bem como na dinâmica de sua luta social. E, também, devido à necessidade constante de pensar a ação educativa no contexto das escolas dos acampamentos e assentamentos do MST, houve a necessidade da busca por fontes que estivessem em consonância com o projeto educativo do Movimento, daí o retorno à pedagogia socialista.

Desde seu início, a prática pedagógica das escolas fundamentou-se na metodologia dos temas geradores de Paulo Freire. No entanto, a pedagogia socialista estava presente nas escolas, principalmente por meio das dinâmicas de organizaçâo do trabalho pedagógico. Em depoimento à Sapelli (2012), Roseli Caldart ressalta que:

O trabalho com temas geradores [...] foi naquele momento considerado mais próximo e mais fácil de compreender do que os Complexos de Estudo de Pistrak. Nos documentos produzidos, entáo, no início dos anos 1990, a ênfase ficou nos temas geradores. Percebeu-se em experiências realizadas a dificuldade de articular o diálogo sobre as questōes da realidade com o estudo dos conteúdos escolares, e a apropriaçáo do conhecimento científico necessário à compreensão das próprias questōes tratadas. [...]

$\mathrm{Na}$ entrevista Caldart afirma que mesmo com a decisão de se adotar o trabalho com os temas geradores, foram incorporados elementos de Pistrak, especialmente suas reflexóes sobre a relação entre escola e trabalho e sobre a auto-organização dos estudantes. Cabe ressaltar que a metodologia dos temas geradores ainda é predominante nas escolas do movimento. É no Estado do Paraná que a experiência soviética da escola única do trabalho vem sendo implementada, como já anunciamos anteriormente. 
Em 2013, treze escolas de assentamentos e acampamentos do Movimento no Paraná, estáo reelaborando suas propostas curriculares para implementação dos complexos de estudos, que possui como referência a experiência da escola única do trabalho do período da Revolução Russa (1917-1931), tendo o trabalho como princípio educativo, eixo curricular orientador e matriz formativa da formação omnilateral.

As novas proposiçóes elaboradas pelo MST apresentam as contribuiçóes de Pistrak e Shulgin na organização do plano de estudos para escolas de educação básica do Movimento. São elas:

1.Tomar o trabalho socialmente necessário como elemento de constituição do plano de estudos da escola permite materializar o trabalho educativo com as diferentes matrizes pedagógicas (trabalho, luta social, organizaçáo coletiva, cultura e história) e organizar a intencionalidade da relação teoria e prática, religando escola e vida. [...] 2.Formular objetivos formativos que integrem o plano de estudos da escola, desdobrando em ação pedagógica específica nossos objetivos de educação mais amplos, consideradas, para cada ciclo etário e etapa da educação básica, as características dos educandos concretos e as exigências formativas do periodo atual. [...] 3.Assumir a educação politécnica como dimensão a ser considerada principal na formulação dos objetivos formativos, que definirão a processualidade de sua abordagem em cada idade e etapa da educação básica e incidirão sobre o conjunto de elementos de constituição do plano de estudos. [...] 4. Tomar a agricultura como objeto de inserção prática e estudo teórico pelos estudantes, fazendo dela o ponto de partida para a educação politécnica nas escolas do assentamento (ou no conjunto das escolas do campo). 5.Tratar o assentamento como lugar de realização prioritária do trabalho socialmente necessário a ser organizado pela escola junto as instâncias ou estruturas organizativas em que se inserem (escola e assentamento) e como objeto de estudo cientifico pelos estudantes, como uma processualidade e abrangência planejadas em conformidade com sua idade e os objetivos formativos e de ensino de cada etapa da educação básica. (MST, 2012, p. 3-8, grifos do autor).

Fica evidente, a partir do exposto, que o plano de estudos almejado pelo Movimento está em consonância com as contribuições teórico-metodológicas da pedagogia socialista, mais especificamente as orientaçôes elaboradas por Pistrak e Shulgin. Estas proposiçôes estão localizadas no plano da estratégia para a materialização do projeto educativo do Movimento. É um novo desafio que se impóe ao MST, o de 
pensar o conteúdo, o método e a forma da escola para avançar na construção de uma pedagogia contra-hegemônica.

Nesse contexto, o trabalho socialmente necessário é o elemento articulador na constituição desta proposta revolucionária de educação que culmina num processo educacional conectado com a atualidade, com a vida, na perspectiva da construção de uma educação politécnica ${ }^{6}$. E, ainda, a experiência com os planos de estudos e com o trabalho socialmente necessário constitui-se como um esforço fundamental para a organização de práticas educativas contra-hegemônicas, bem como para construção de instrumentos para elaboração de uma crítica radical ao modelo de escolarização atual, já que tal proposta faz a crítica à educação unilateral presente na sociedade capitalista.

\section{Considerações finais}

Este artigo teve como objetivo principal a discussão sobre a atualidade das contribuiçóes da pedagogia socialista para a Pedagogia do Movimento, por meio da proposta de implementaçáa do plano de estudos de Pistrak e da categoria trabalho socialmente necessário pensada por Shulgin.

A discussão realizada pautou-se num estudo das obras escritas por Pistrak e Shulgin, as quais relatam a experiência da escola única do trabalho no período revolucionário russo, bem como seus princípios teórico-metodológicos. Descreve-se de maneira sucinta a experiência em curso nas escolas itinerantes do Estado do Paraná com o plano de estudos, destacando suas contribuiçôes e desafios postos ao movimento.

Assim, a partir da elaboração deste artigo, as reflexóes indicaram que o Movimento Sem Terra ensaia e engendra, na atualidade, a possibilidade concreta da construçáo de uma pedagogia pautada nos princípios da pedagogia socialista, estabelecendo o diálogo com os educadores russos da escola única do trabalho. E que o caminho já percorrido pelo MST, com a metodologia dos temas geradores e a pedagogia socialista, possibilitou chegar a novas discussōes sobre a necessidade da organização dos planos de estudos, pautado nos princípios da escola única do trabalho.

Por fim, conclui-se que esta experiência vem alterando a forma escolar, ao refletir sobre a possibilidade da construção de uma escola comprometida com sujeitos concretos e almejar um processo pedagógico teórico-prático que venha possibilitar a cada educando sem-terra a consciência crítica da realidade onde está inserido e o compromisso com a luta social do movimento.

\section{Notas}


${ }^{1}$ Sobre estudos que avaliam a experiência revolucionária russa, ver: Reed (2010), Reis Filho (2003), Hobsbawn (1995) e Paulino (2010).

2 Para compreendermos o Estado após o advento da Revolução Russa em 1917, é necessário considerar, como demonstra Trotsky (1967, p. 23), “a lentidão com que o país se desenvolveu, apresentando como consequência uma economia atrasada, uma estrutura social primitiva e o baixo nível cultural”. Isso implicou na necessidade da centralização do Estado para dar conta de promover o desenvolvimento econômico e cultural da Rússia da época. Assim, Lênin e os bolcheviques vão formular uma nova concepção de Estado, o chamado Estado forte, pois, de acordo com Paulino (2010, p. 73, grifo do autor), "na falta de acumulação burguesa na Rússia, pré-condição para instauração do socialismo, o Estado, sob a forma da ditadura do proletariado, teria que assumir outras funçôes, agora econômica-culturais".

${ }^{3}$ Em setembro 1918 é publicada a Deliberação sobre a escola única do trabalho, pelo Comitê Central do Partido Comunista (bolchevique). Em outubro do mesmo ano é publicado pelo Narkompros um documento intitulado Princípios Fundamentais da Escola Única do Trabalho. Nesse ano, há a criação das Escolas Experimentais Demonstrativas, as Escolas-Comunas, que se organizavam a partir dos princípios da Escola Única do Trabalho. Freitas (2012) esclarece que a terminologia escola única do trabalho estava vinculada à ideia de uma a escola comprometida com a construçáo de uma nova sociedade, sendo instrumento a favor da conscientização e emancipação da classe trabalhadora, bem como única por não ser dual, ou seja, há uma forma de organização escolar e curricular comum a todos. E ainda, do trabalho, por apresentar a compreensão do trabalho como princípio educativo, com ênfase na formação politécnica.

${ }^{4}$ Para Marx (2006, p .112, grifos do autor), “[...] a alienação do trabalhador do seu produto de trabalho significa náo só que o trabalho se transforma em objeto, assume uma existência externa, mas que existe independentemente, fora dele é a ele estranho, e se torna uma força hostil e antagônica".

${ }^{5}$ A expressão Sem Terra, com letras maiúsculas e sem hífen, de acordo com Caldart (2001, p. 223) “[...] é o nome próprio que identifica os sem-terra do MST. A expressão 'sem-terra' indica a categoria social de trabalhadores e trabalhadoras do campo que não têm terra e que passam a requerê-la como direito. Trata-se de um vocábulo recente nos dicionários de língua portuguesa, uma das conquistas culturais da luta pela terra no Brasil. Mas em seu nome, os Sem Terra, mantêm a grafia original de seu nascimento, como sujeitos que criaram o MST".

${ }^{6}$ É importante destacar que, nos escritos de Shulgin, a formação politécnica é tida como urgente e necessária na consolidação da escola única do trabalho. Nela está contida a perspectiva da formação humana multilateral. Na avaliação de Freitas (2013, p. 9), Shulgin "[...] propóe um sistema politécnico que vai desde os anos iniciais até o ensino superior: isso chama politecnismo. A força da categoria 'trabalho' como articuladora do processo deformação da juventude emerge com plenitude, associada ao conceito de autodireção e de atualidade”. 


\section{REFERÊNCIAS}

BOGO, Ademar. O pedagogo da esperança e da liberdade. In: MST. Movimento dos Trabalhadores Sem Terra. Paulo Freire vive! Hoje, 10 anos depois. São Paulo: MST, 2007.

CALDART, Roseli Salete. A educação das crianças nos acampamentos e assentamentos. In: GÖRGEN, Frei Sérgio Antônio; STÉDILE, João Pedro. Assentamentos: a resposta econômica da Reforma Agrária. Petrópolis: Rio de Janeiro, 1991.p. 85-111.

CALDART, Roseli Salete. Educação em movimento: formação de educadores e educadoras no MST. Petrópolis, RJ: Vozes, 1997.

CALDART, Roseli Salete. Escola é mais do que escola na pedagogia do movimento Sem Terra. 1999. Tese. (Doutorado em educação) - Universidade Federal do Rio Grande do Sul, Porto Alegre, RS, 1999.

CALDART, Roseli Salete. O MST e a formação dos sem terra: o movimento social como princípio educativo. Estudos Avançados, São Paulo, v.15, n.43, p. 207-224, 2001.

CALDART, Roseli Salete. Por uma Educação do Campo: traços de uma identidade em construçấo. In: KOLLING, Edgar J.; CERIOLI, Paulo Ricardo; CALDART, Roseli Salete (Org.). Educação do campo: identidades e políticas públicas. Brasília, DF: Articulação Nacional por Uma Educaçáo do Campo, 2002. p. 25-36.(Coleção Por uma Educação Básica do Campo, n. 4).

CALDART, Roseli Salete. Pedagogia do Movimento Sem Terra. 3. ed. São Paulo: Expressão Popular, 2004.

CALDART, Roseli Salete. O MST e a escola: concepção de educação e matriz formativa. In: CALDART, Roseli Salete (Org.). Caminhos para transformação da escola: reflexóes desde práticas da licenciatura em educação do campo. São Paulo: Expressão Popular, 2011

FREITAS, Luiz Carlos. A luta por uma pedagogia do meio: revisitando o conceito. In: PISTRAK, Moisey. A Escola-Comuna. Tradução de Luiz Carlos de Freitas e Alexandra Marenich. São Paulo: Expressão Popular, 2009.

FREITAS, Luiz Carlos de. Escola Única do Trabalho. In: CALDART, Roseli Salete et al. (Org.). Dicionário da Educaçáo do Campo. São Paulo: Expressão Popular, 2012. 
p. 337-341.

FREITAS, Luiz Carlos de. Prefácio. In. SHULGIN, Viktor Nikolaevich. Rumo ao politecnismo (artigos e conferências). Tradução de Alexey Lavarev e Luiz Carlos de Freitas. São Paulo: Expressão Popular, 2013.

FRIGOTTO, Gaudêncio. Projeto societário contra-hegemônico e educação do campo: desafios de conteúdo, método e forma. In: MUNARIM, Antônio et al. (Org.). Educação do Campo: reflexóes e perspectivas. Florianópolis, SC: Insular, 2010. p. 19-46.

HOBSBAWN, Eric. Era dos Extremos: o breve século XX: 1914-1991. Tradução de Marcos Santarrita. São Paulo: Companhia das Letras, 1995.

KRUPSKAIA, Nadezhda K. Prefácio. In. PISTRAK, Moisey M. A Escola-Comuna. Tradução de Luiz Carlos de Freitas e Alexandra Marenich. São Paulo: Expressão Popular, 2009.

LAFARGUE, Paul. O direito à preguiça. Tradução de Teixeira Coelho Netto. São Paulo: Hucitec, 1999.

LUKÁCS, George. Ontologia do Ser Social: os princípios ontológicos fundamentais de Marx. Tradução de Carlos Nelson Coutinho. São Paulo: Livraria e Editora Ciências Humanas, 1979.

MANACORDA, Mário A. Marx e a pedagogia moderna. Tradução de Newton Ramos de Oliveira. São Paulo: Cortez, 1991.

MARX, Karl. Manuscritos Econômicos-Filosóficos. Tradução de Pietro Nasseti. São Paulo: Martin Claret, 2006.

MST. Movimento dos Trabalhadores Sem Terra. Princípios da educação no MST. Porto Alegre: MST, 1996. (Caderno de Educação, n. 8).

MST. Movimento dos Trabalhadores Sem Terra. Dossiê MST e a escola: documentos e estudos 1990 e 2001. São Paulo: Editora Expressão Popular, 2005. (Caderno Educação, n. 13).

MST. Movimento dos Trabalhadores Sem Terra. Proposiçóes às escolas de educação básica das áreas de Reforma Agrária. In: SEMINÁRIO ESCOLAS REGIÃO SUL: formas de organização do Plano de Estudos, Educação Politécnica e Agricultura Camponesa. 2012,Veranópolis. Anais... Veranópolis: Setor de Educação do MST; Instituto de Educação Josué de Castro, 2012.

PAULINO, Robério. Socialismo no século XX: o que deu errado? 2. ed. São Paulo: 
Letras do Brasil, 2010.

PISTRAK, Moisey. Fundamentos da escola do trabalho. Tradução de Daniel Aarão Reis Filho. 3. ed. São Paulo: Expressáo Popular, 2003.

PISTRAK, Moisey. A Escola-Comuna. Traduçáo de Luiz Carlos de Freitas e Alexandra Marenich. São Paulo: Expressão Popular, 2009.

REED, John. Dez dias que abalaram o mundo. Tradução de José Octávio. São Paulo: Penguin Classics Companhia das Letras, 2010.

REIS FILHO, Daniel Aarão. As revoluçóes russas e o socialismo soviético. São Paulo: Editora da UNESP, 2003. (Coleção Revoluções do século XX).

ROSSI, Wagner. Pedagogia do Trabalho. São Paulo: Moraes, 1981.

SANTOS, Franciele Soares dos. Formação de educadores militantes no MST: a experiência do curso de Pedagogia da Terra na Unioeste/PR. 2009. 145f. Dissertação (Mestrado em Educação) - Universidade Federal de Santa Catarina, Florianópolis, SC. 2009.

SAPELLI, Marlene Lúcia Siebert. De Paulo Freire a Pistrak. In: FÓRUM DE EDUCAÇÃO DO CAMPO DA REGIÃO SUL DO RS, 1., 2012, Pelotas. Anais... Pelotas, RS: SIFEDOC, 2012.

SHULGIN, Viktor Nikolaevich. Rumo ao politecnismo (artigos e conferências). Tradução de Alexey Lavarev e Luiz Carlos de Freitas. São Paulo: Expressão Popular, 2013.

TROTSKY, Leon. A história da Revolução Russa. Tradução de E. Huggins. Rio de Janeiro: Saga, 1967. 1v. 
The present contributions of Moisey Pistrak And Viktor M. N. Shulgin for the pedagogy of Brazil's Landless Workers Movement

\begin{abstract}
The aim of this article is to contribute to the debate about the relevance of socialist pedagogy to the advances in the pedagogy of Landless Workers Movement (MST, in the original acronym), through the proposed implementation of Moisey M. Pistrak's studies plan and of the category of necessary social labor, elaborated by Viktor N. Shulgin. For its elaboration we conducted a bibliographic study of these authors' works as well as of those of Caldart and of documents of the Movement. The results indicate that the Landless Movement rehearses and engenders today the possibility of constructing a pedagogy based on the principles of socialist pedagogy, whose central category is work, thus establishing a dialogue with the Russian educators. We concluded that by establishing committed relationships with concrete subjects, aiming the critical awareness of reality and the commitment to the social movement's struggle, the experience of socialist pedagogy is changing beyond the content, the method and the school form.
\end{abstract}

Keywords: Socialist Pedagogy. Brazil's Landless Workers Movement. Work and Education.
L'actualité de la contributions de Moisey M. Pistrak et Viktor N. Shulgin pour la pedagogie de Movimento dos Trabalhadores Sem Terra

\section{Résumé}

L'objectif avec cet article était de contribuer au débat sur la pertinence de la pédagogie socialiste aux progrès de la pédagogie du Mouvement Sans Terre (MST), avec cette proposition pour la mise Le programme de Pistrak et la catégorie de travail socialement nécessaire, élaboré par Shulgin. Pour son efficacité a été menée l'étude bibliographique de ces auteurs ainsi que des œuvres d'Caldart, et des documents du Mouvement. Les résultats indiquent que le Mouvement des Sans Terre répète et engendre aujourd'hui, établir un dialogue avec les éducateurs russes, la possibilité concrète de la construction d'une pédagogie fondée sur les principes de la pédagogie socialiste, dont la catégorie centrale est un travail. Il est conclu que, en établissant des relations engagées avec des sujets concrets, visent à la conscience critique de la réalité et de l'engagement à la lutte de mouvement social, cette expérience est en train de changer, audelà du contenu, la méthode et la forme de l'école.

Mots-clés: Pédagogie des MST. Pédagogie Socialiste. Les Plans d'Études. 


\section{Franciele Soares dos Santos}

E-mail: sfranceli@yahoo.com.br

\section{Conceiçáo Paludo}

E-mail:c.paludo@terra.com.br

Recebido em: 17/5/2014 Aprovado em: 21/7/2015 